\title{
ARTICLE
}

Received 17 Feb 2014 | Accepted 14 Oct 2014 | Published 21 Nov $2014 \quad$ DOl: 10.1038/ncomms6564

\section{Erosion influences the seismicity of active thrust faults}

Philippe Steer ${ }^{1}$, Martine Simoes ${ }^{2}$, Rodolphe Cattin ${ }^{3} \&$ J. Bruce H. Shyu ${ }^{4}$

Assessing seismic hazards remains one of the most challenging scientific issues in Earth sciences. Deep tectonic processes are classically considered as the only persistent mechanism driving the stress loading of active faults over a seismic cycle. Here we show via a mechanical model that erosion also significantly influences the stress loading of thrust faults at the timescale of a seismic cycle. Indeed, erosion rates of about $\sim 0.1-20 \mathrm{mmyr}^{-1}$, as documented in Taiwan and in other active compressional orogens, can raise the Coulomb stress by $\sim 0.1-10$ bar on the nearby thrust faults over the inter-seismic phase. Mass transfers induced by surface processes in general, during continuous or short-lived and intense events, represent a prominent mechanism for inter-seismic stress loading of faults near the surface. Such stresses are probably sufficient to trigger shallow seismicity or promote the rupture of deep continental earthquakes up to the surface.

\footnotetext{
${ }^{1}$ Géosciences Rennes, Université Rennes 1 and CNRS UMR 6118, 35042 Rennes, France. ${ }^{2}$ Institut de Physique du Globe de Paris, Sorbonne Paris Cité, University Paris Diderot, UMR 7154 CNRS, F-75005 Paris, France. ${ }^{3}$ Géosciences Montpellier, Université Montpellier II and CNRS UMR 5243,34090 Montpellier, France. ${ }^{4}$ Department of Geosciences, National Taiwan University, Taipei 10617, Taiwan. Correspondence and requests for materials should be addressed to P.S. (email: philippe.steer@univ-rennes1.fr).
} 
$\mathrm{T}$ he evolution of the Earth's topography is dictated by the interactions between tectonics, climate and surface processes (that is, erosion and sedimentation). Whether this evolution influences tectonic deformation during mountain building has been widely debated. It is now well accepted that surface evolution can drive the localization and intensity of tectonic deformation over geological times ${ }^{1-3}(1-10 \mathrm{Myr})$. At intermediate time scales (10 kyr-1 Myr), erosion and the subsequent isostatic rebound can favour slip along specific fault planes $^{4-7}$. However, the link between surface processes and the stress loading of faults during the seismic cycle (0.1-1 kyr), and in turn the associated deformation mechanisms, remains unsubstantiated.

Faults represent the main mechanical discontinuities of the elastic-brittle Earth's upper crust. They accommodate tectonic deformation by slipping, mostly during earthquakes ${ }^{8}$. These seismogenic faults are rooted down dip in viscous shear zones $^{8-10}$. It is generally accepted that, during the inter-seismic phase (that is, before an earthquake), continuous viscous flow in these deep shear zones leads to the elastic stress loading of active faults closer to failure, and that during the co-seismic phase (that is, during an earthquake), failure and slip occur along the previously locked fault planes, followed by post-seismic stress relaxation ${ }^{4,8}$. Fault failure is commonly defined by the mean of the Coulomb stress change, $\Delta C F F=\Delta \tau+\mu^{\prime} \cdot \Delta \sigma_{\mathrm{n}}$, a function of the fault effective friction $\mu^{\prime}$, the shear $\Delta \tau$ (positive in the direction of slip) and normal $\Delta \sigma_{\mathrm{n}}$ (positive if the fault is unclamped) stress changes ${ }^{8,11}$. Earthquakes can be triggered by tectonic stresses, but also by Coulomb stresses due to episodic and short-lived events such as hydrologic ${ }^{12}$ or snow loading ${ }^{13}$, nearby earthquakes ${ }^{14-17}$ and slow-slip events ${ }^{18}$.

Here, we show that surface processes significantly contribute to the Coulomb stress loading of thrust faults during the seismic cycle. To illustrate and then demonstrate our point, we consider a mountain range in Taiwan where the rates of $\operatorname{erosion}^{19}$ and tectonic deformation ${ }^{20,21}$ are extremely high and among the bestdocumented in the world. We then investigate how erosion influences the stress loading of thrust faults using a simple model for the seismic cycle.

\section{Results}

Coulomb stress changes induced by erosion in Taiwan. Our first model quantifies the Coulomb stress change $\triangle C F F$ generated by erosional unloading, as constrained from fluvial suspended sediment load measured over the $30 \mathrm{yr}$ before the $1999 M_{\mathrm{w}} 7.6$ Chi-Chi earthquake in central Taiwan ${ }^{19}$ (Fig. 1 and Methods). The three dimensional (3D) velocity field $\mathbf{v}$, strain rate $\dot{\varepsilon}$ and stress rate $\dot{\boldsymbol{\sigma}}$ tensors induced by erosion are computed in an elastic half-space using a Boussinesq approach (Fig. 1c and Methods). We use simplified geometries for active thrust faults located in the foothills of Taiwan ${ }^{22}$ (for details, see Methods) and assume a dip angle $\alpha$ of $30^{\circ}$, a $15 \mathrm{~km}$ deep brittle-ductile transition $^{22}$ and an effective friction $\mu^{\prime}$ of 0.5 to compute Coulomb stress changes per unit time (or loading rates) $\triangle C F F$ due to erosional unloading on these faults. We find a maximum value of $\sim 4 \times 10^{-3}$ bar yr $^{-1}$ for the Coulomb stress change $\triangle C F F$ induced by erosional unloading on the Liuchia fault system (number 8 on Fig. 1) in southwestern Taiwan. Despite a low topographic relief, this area has the highest erosion rates documented in Taiwan (up to $24 \mathrm{~mm} \mathrm{yr}^{-1}$ ), which are proposed to be controlled locally by a low substrate strength, a high storminess and a high seismic moment release rate ${ }^{19}$. However, most of the thrust faults located in the foothills still display a significant $\triangle C F F$ of $\sim 0.5 \times 10^{-3} \mathrm{bar} \mathrm{yr}^{-1}$, including the Chelungpu fault (number 3) that ruptured during the

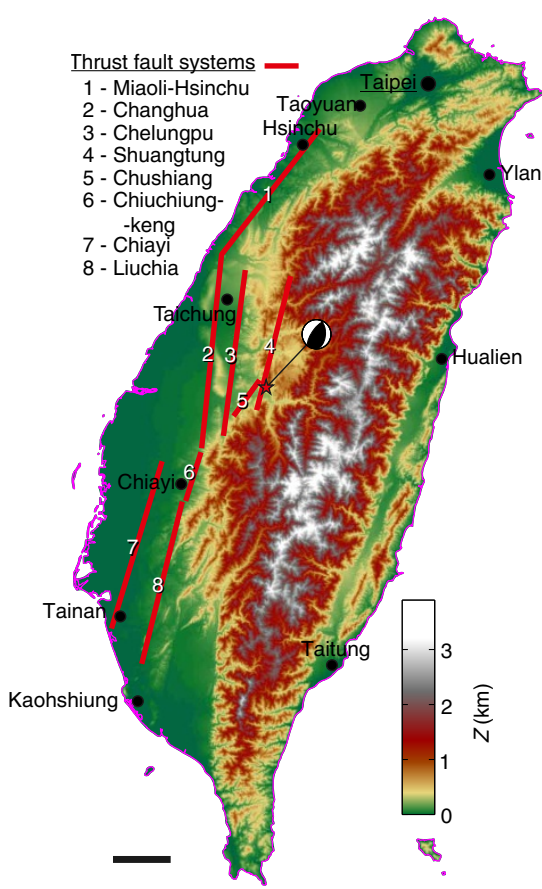

b

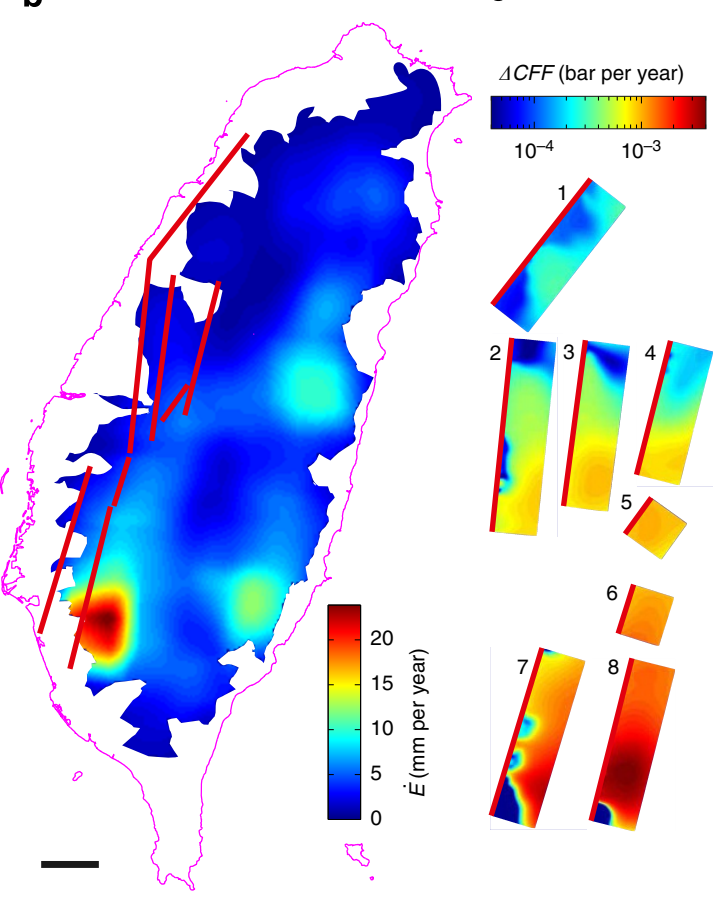

Figure 1 | Faults stress loading rates induced by erosion in the foothills of Taiwan. (a) Topography, simplified main thrust fault systems (red lines and numbers from 1-8) and location of the $1999 M_{w} 7.6$ Chi-Chi earthquake epicenter (red star) that ruptured the Chelungpu fault (number 3). (b) Inter-seismic erosion rates before the Chi-Chi earthquake, as calculated from fluvial suspended sediment measurements with a 5-km grid resolution, smoothed at the catchment scale using a circular moving mean with $30-\mathrm{km}$ diameter ${ }^{19}$. (c) Erosion induced Coulomb stress loading rates $\triangle C F F$ calculated on the fault planes. The horizontal solid black lines represent scale bars of $50 \mathrm{~km}$. 
a

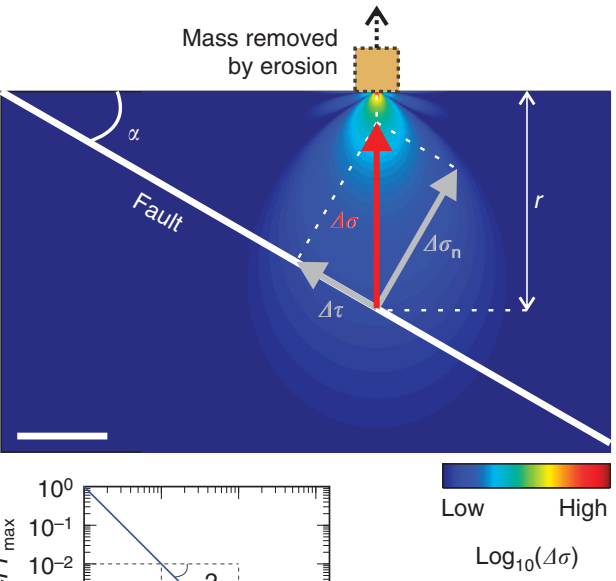

b

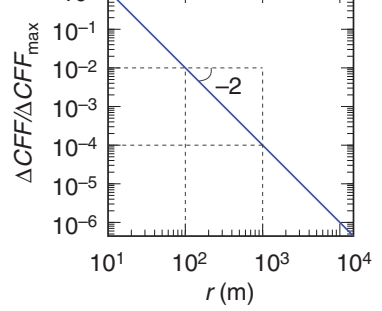

$\triangle C F F$ (bar per year) $10^{-5} 10^{-4} 10^{-3}$

C

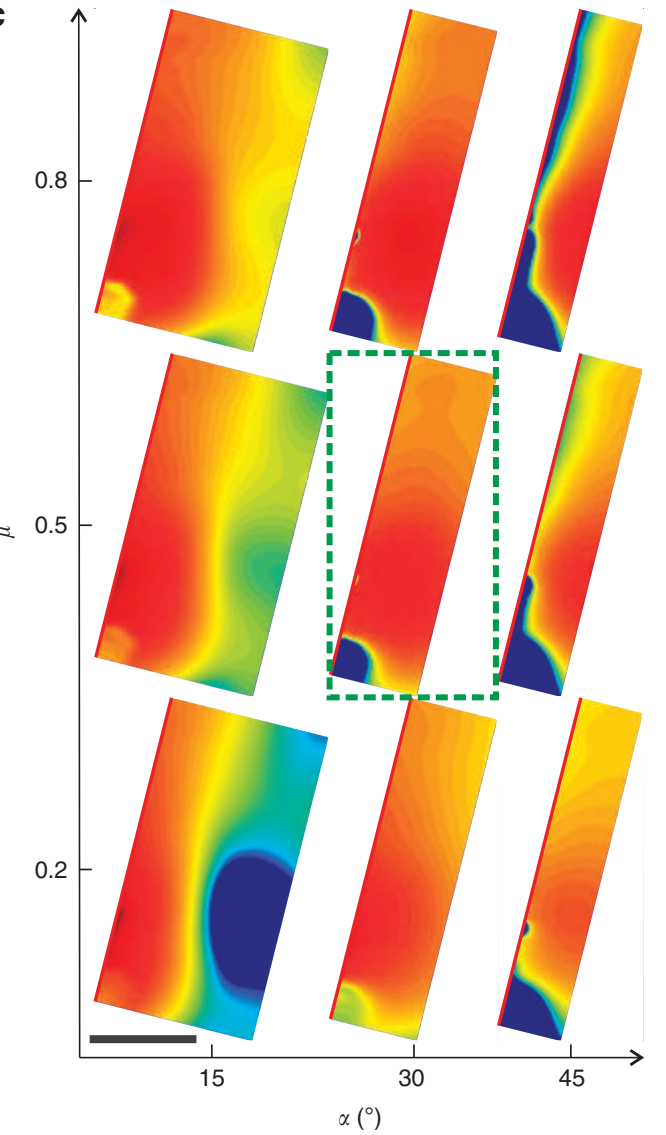

Figure 2 | Mechanism of Coulomb stress loading of a thrust fault by surface erosion. (a) Distribution of stress increment $\Delta \sigma$ (here purely illustrative) induced by a punctual erosion at the surface, increasing both the tangential $\Delta \tau$ (driving effect) and the normal stresses $\Delta \sigma_{\mathrm{n}}$ (unclamping effect). The white solid line indicates a scale bar of $2.5 \mathrm{~km}$. (b) The resulting fault Coulomb stress change $\triangle C F F$ decreases with the square of the vertical distance $r$ between the fault plane and where erosion occurs (assuming $\alpha=30^{\circ}$ and $1 \mathrm{~m}$ of erosion). (c) Sensitivity of $\triangle C F F$ induced by erosion to the fault dip angle $\alpha$ and effective friction $\mu^{\prime}$, taking the Liuchia fault system as an example. The black solid line indicates a scale bar of $25 \mathrm{~km}$. The model in the dashed green box is equivalent to the one in Fig. 1 and $\Delta \tau$ and $\Delta \sigma_{\mathrm{n}}$ are reported in Supplementary Fig. 1.
Chi-Chi earthquake. Integrated over a seismic cycle duration ${ }^{23}$ of $\sim 500 \mathrm{yr}$, a $\triangle C F F$ of 0.5 to $4 \times 10^{-3}$ bar yr $^{-1}$ due to erosional unloading gives a net Coulomb stress change of $0.25-2.0$ bar. Similar values of Coulomb stress change are documented elsewhere to contribute significantly to the stress loading and dynamics of active faults ${ }^{12-18}$. This suggests that erosional unloading can significantly influence the short-term dynamics of faults.

Erosional unloading modifies the Coulomb stress change on a fault plane in two ways: (1) it decreases the normal stress and unclamps the fault, and (2) it increases the tangential stress (Fig. 2a). The increment of stress on a fault plane is proportional to the amount of erosion, but decreases with the square of the distance $r$ between the fault plane and where erosion occurs (Fig. 2b). Therefore, the amplitude of erosional Coulomb stress loading on a fault is sensitive (1) to the effective friction $\mu^{\prime}$, which modulates the effect of erosion on the normal stress, and (2) to the fault dip angle $\alpha$, which decomposes the stresses into fault normal and tangential components and controls the distance of the fault plane to the surface. For instance, a higher effective friction $\mu^{\prime}$ of 0.8 and a lower dip angle $\alpha$ of $15^{\circ}$, therefore, result in increasing the induced $\triangle C F F$ up to $\sim 1 \times 10^{-2} \mathrm{bar} \mathrm{yr}^{-1}$ for the Liuchia fault system (Fig. 2c). In addition, the stresses modelled here are invariant with the Young modulus of the material, as we are considering a linear elastic material subjected to a surface pressure load (and not to a surface displacement).

Stresses induced by erosion during the seismic cycle. The above computations consider inter-seismic erosion rates calculated from data acquired during the $30 \mathrm{yr}$ preceding the Chi-Chi earthquake $^{19}$. Even though its amplitude relative to co-seismic rock uplift is debated, co- and post-seismic erosional unloading represent a major contribution to erosion in seismic areas ${ }^{24-2}$. In mountain belts with hillslopes close to failure, co-seismic ground motion and acceleration can induce a significant amount of landslides ${ }^{28}$. The sediments produced by these landslides are then transported by rivers mainly during subsequent floods. This post-seismic landscape relaxation phase has a documented potential duration 25,26 of years to decades, one order of magnitude shorter than a complete seismic cycle. Therefore, the contribution of co- and post-seismic erosion to the stress loading of active faults also needs to be evaluated.

To assess the relative contribution of inter-seismic erosion, co-/post-seismic erosion and tectonics to the Coulomb stress loading of faults, we develop a simple model of the seismic cycle that accounts for the effect of both erosion and tectonics (Fig. 3 and Methods). We assume a steady-state landscape over the seismic cycle, that is, rock uplift rates $\dot{U}$ are balanced by erosion rates $\dot{E}$ over this time scale. Because of the response-time of the geomorphic system to climate or tectonic perturbations and because of their stochastic properties ${ }^{29}$, this assumption is probably not valid in most settings. However, it offers a simple and self-consistent approach for modelling first-order surface processes during the seismic cycle. A Boussinesq approach is used to compute $\mathbf{v}, \dot{\boldsymbol{\varepsilon}}$ and $\dot{\boldsymbol{\sigma}}$, whereas the tectonic stresses and uplift (and therefore erosion) are calculated using dislocations embedded in an elastic half-space ${ }^{30}$. The effects of tectonic deformation during the inter- and co-seismic phases are accounted for by slip on a deep shear zone and on a shallow brittle fault, respectively ${ }^{9,31}$. This seismic cycle model is valid when considering a fault that is fully locked during the interseismic phase, as it is proposed for the thrust faults located in the western foothills of Taiwan ${ }^{32-34}$.

For comparison with faults in the foothills of Taiwan, we define a reference model with a fault trace length of $80 \mathrm{~km}$ and a dip 
a

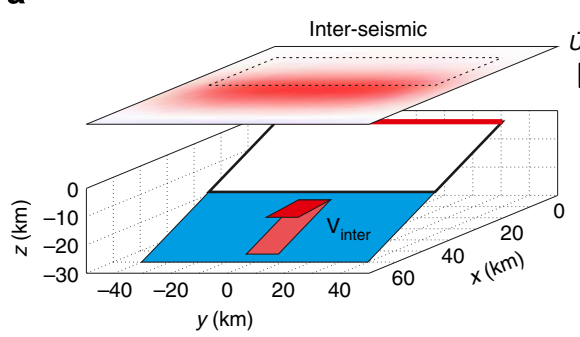

C

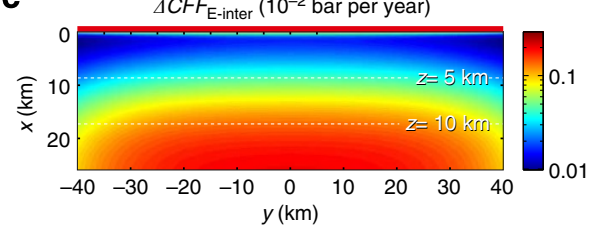

e

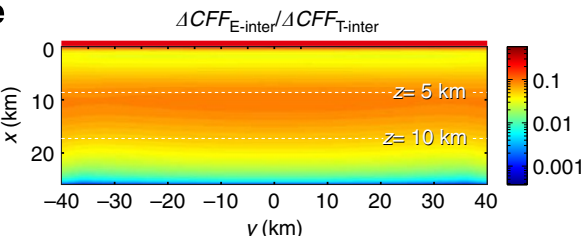

g

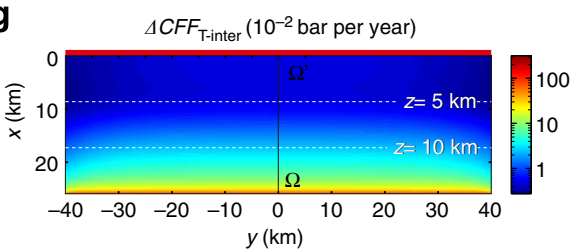

b

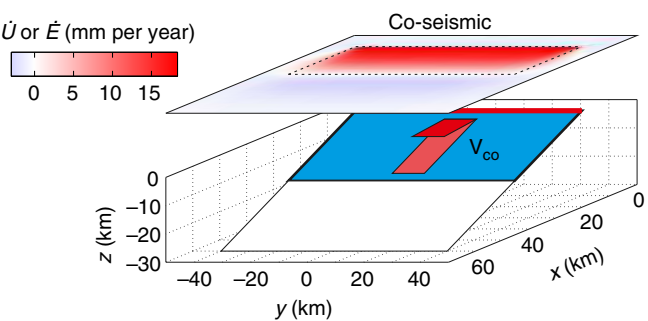

d

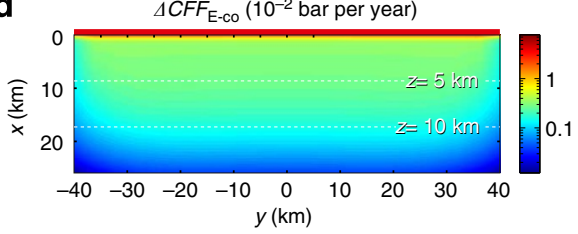

f
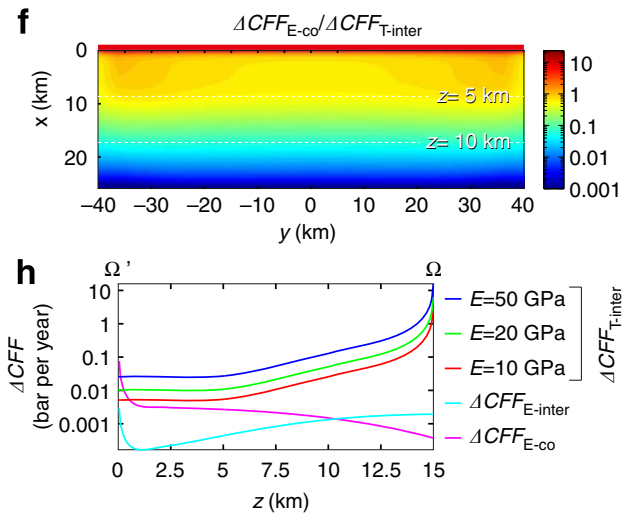

Figure 3 | Erosional versus tectonic driven Coulomb stress loading of faults during the seismic cycle. Model 3D geometry and modelled surface rock uplift rate $\dot{U}$ during the (a) inter- and (b) co-seismic phases averaged over the entire seismic cycle. The averaged tangential velocities of the shallow fault $V_{\text {co }}$ and of the deep shear zone $V_{\text {inter }}$ are equal to $40 \mathrm{~mm} \mathrm{yr}^{-1}$. Erosional Coulomb stress loading rates of the fault obtained by equating erosion rates $\dot{E}$ to surface uplift rates $\dot{U}$ for the (c) inter-seismic $\triangle C F F_{\mathrm{E}-\text { inter }}$ and (d) co-seismic $\triangle C F F_{\mathrm{E}-\mathrm{co}}$ phases. Ratios of (e) inter-seismic and (f) co-seismic erosional Coulomb stress loading rates over $(\mathbf{g})$ the inter-seismic tectonic Coulomb stress loading rate $\Delta C F F_{\text {T-inter }} \Delta \tau$ and $\Delta \sigma_{\mathrm{n}}$ are reported in Supplementary Figure 2. (h) Spatial variation of Coulomb stresses along the fault plane (cross-section $\Omega$ - $\Omega^{\prime}$ ) considering different Young moduli ( $E=10,20$ and $50 \mathrm{GPa}$ ) that only influences the tectonics stresses and not the stresses induced by erosion.

angle of $30^{\circ}$, while keeping all the other mechanical properties identical. We also impose a slip velocity $V_{\text {inter }}$ of $40 \mathrm{~mm} \mathrm{yr}^{-1}$ on the shear zone during the inter-seismic phase, and $V_{\text {co }}$ of $40 \mathrm{~mm} \mathrm{yr}^{-1}$ on the associated brittle fault during the co-seismic phase. This model setup provides only a rough approximation of the seismic cycle at the scale of the whole western foothills of Taiwan. Indeed, deformation is partitioned between several active thrust faults in this area that are probably rooted down at depth into a single decollement with a total slip of $\sim 40 \mathrm{~mm} \mathrm{yr}^{-1}$ (refs 21,33). In addition, because our goal is to quantify the co- and post-seismic erosional unloading rates during the landscape relaxation phase following large earthquakes ${ }^{25,26}$, we compute co-seismic slip velocity averaged over the seismic cycle rather than co-seismic instantaneous displacement. Note that these two approaches are strictly equivalent in an elastic model.

In our modelling, inter- and co-seismic rock uplift (and erosion) rates are similar and up to $\sim 20 \mathrm{~mm} \mathrm{yr}^{-1}$ (Fig. 3). We assume no time modulation of inter- and co-seismic erosion and both modelled erosion rates are applied over the entire duration of one seismic cycle. Despite similar erosion rates, co-seismic erosional unloading induces fault Coulomb stress loading $\triangle C F F_{\mathrm{E}-\text { co }}$ of up to $\sim 8 \times 10^{-2}$ bar yr $^{-1}$ at very shallow depth $(<1 \mathrm{~km})$, which is about 30 times the maximum stress loading induced by inter-seismic erosion $\triangle C F F_{\mathrm{E}-\text { inter }}$. Indeed, the maxima of co-seismic uplift of the surface (and erosion) occurs over the shallow portion of the fault, therefore at a shorter distance to the fault plane than the maxima of inter-seismic erosion (Fig. 3). Despite a rapid decrease with depth, $\triangle C F F_{\mathrm{E}-\mathrm{co}}$ is still greater than $\sim 0.5 \times 10^{-2} \mathrm{baryr}^{-1}$ at a depth of $5 \mathrm{~km}$. Coulomb stress loading $\triangle C F F_{\mathrm{E}-\text { inter }}$ induced by inter-seismic erosion displays two

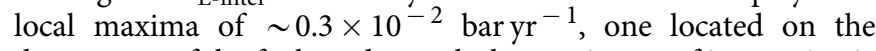
deeper part of the fault underneath the maximum of inter-seismic erosion, and the second one close to the fault tip owing to its proximity with the surface.

We then compare fault Coulomb stress loading rates induced by erosion with those induced only by tectonics during the interseismic phase $\triangle C F F_{\mathrm{T}-\text { inter. In terms of amplitude, Coulomb stress }}$ loading rates due to tectonics are up to two or four orders of magnitude greater than those related to erosion, in particular for the deeper part of the fault. However, at shallower depths $(<5 \mathrm{~km})$, Coulomb stress loading rates due to co-seismic erosion and tectonics are of the same order of magnitude, and the ratio $\triangle C F F_{\mathrm{E}-\mathrm{co}} / \triangle C F F_{\mathrm{T} \text {-inter }}$ even reaches $\sim 20$ close to the surface (Fig. 3). At the contrary, Coulomb stress loading rates associated with inter-seismic erosion, which is maximum on the deeper and shallower part of the fault, do not dominate tectonic stresses. The ratio $\triangle C F F_{\mathrm{E}-\text { inter }} / \triangle C F F_{\mathrm{T} \text {-inter }}$ only reaches $\sim 0.1$ at intermediate depths $(5-10 \mathrm{~km})$ and $\sim 0.6$ close to the surface. Because the upper crust displays a very long stress relaxation time associated with high effective viscosities, these Coulomb stress changes 


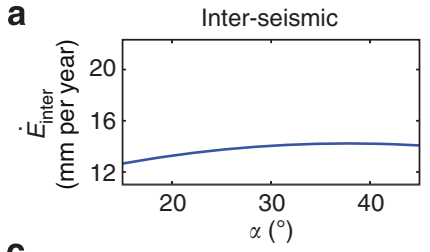

C

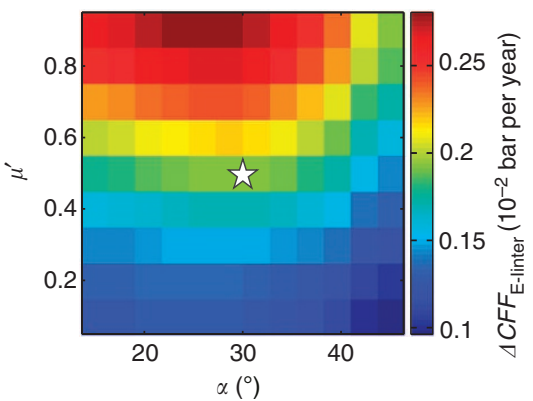

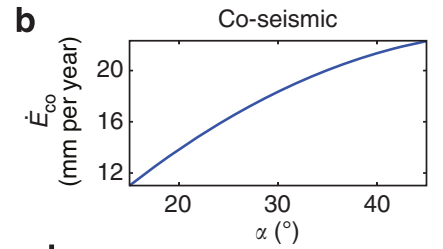

d

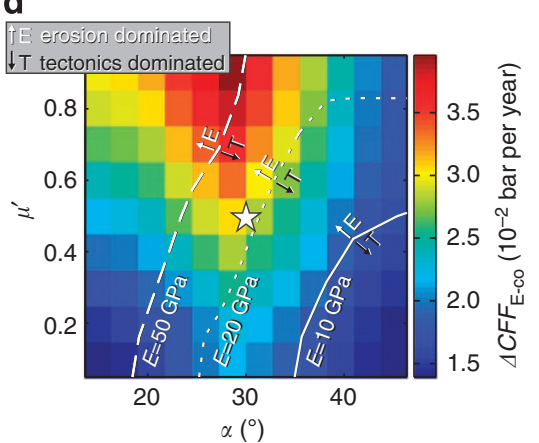

Figure 4 | Sensitivity of model results to the model parameters. Maximum surface erosion rates obtained during the (a) inter-seismic $\dot{E}_{\text {inter }}$ and the (b) co-seismic $\dot{E}_{\mathrm{co}}$ periods as a function of the fault and shear zone dip angle $\alpha$. Maximum fault Coulomb stresses induced by erosion during (c) inter-seismic $\triangle C F F_{\mathrm{E}-\text { inter }}$ and (d) co-seismic $\triangle C F F_{\mathrm{E}-\mathrm{co}}$ periods, which are function of the dip angle $\alpha$ and of the effective friction $\mu^{\prime}$, are shown with a plain colour map. White lines indicate the limits of tectonics (black arrow) versus erosion (white arrow) dominated Coulomb stresses in the model parameter space for varying values of the Young modulus $E(10,20$ and $50 \mathrm{GPa}$ ). The reference model is represented by a white star. We consider that Coulomb stresses induced by erosion dominate tectonic stresses when at least one element of the fault is dominated by erosional stresses. For the inter-seismic erosion induced stresses, we here only consider the deep part of the fault.

induced by erosion can be accumulated over the time scale of a seismic cycle ( $\sim 500 \mathrm{yr})$. On the other hand, increasing the Young modulus from the reference value $(10 \mathrm{GPa})$ by a factor of 2 $(20 \mathrm{GPa})$ or $5(50 \mathrm{GPa})$ results in increasing the Coulomb stress change induced by tectonics $\triangle C F F_{\mathrm{T} \text {-inter }}$ by a factor of 2 or 5 and decreasing the ratios $\triangle C F F_{\mathrm{E}-\text { inter }} / \triangle C F F_{\mathrm{T} \text {-inter }}$ and $\triangle C F F_{\mathrm{E}-\mathrm{co}}$ $\triangle C F F_{\mathrm{T}-\text { inter }}$ by the same factor (Fig. $3 \mathrm{~h}$ ). However, these results still demonstrate (1) that erosion can contribute significantly to thrust fault stress loading during the seismic cycle, and (2) that erosion can even be one of the dominant stress loading mechanisms for the shallower parts of thrust fault planes.

Model sensitivity analysis. To assess the sensitivity of our results to the model parameters, we design a set of models similar to the reference model, but with varying values of the effective friction $\mu^{\prime}(0.1-0.9)$, the Young modulus $E(10,20$ and $50 \mathrm{GPa})$ and the fault and shear zone dip angle $\alpha\left(15\right.$ to $\left.45^{\circ}\right)$. For the sake of simplicity, we keep the depth of the brittle-ductile transition at $15 \mathrm{~km}$, which in turn implies that the surface area of the brittle fault increases when decreasing $\alpha$. Using this modelling approach, erosion rates during the inter-seismic $\dot{E}_{\text {inter }}$ and the co-seismic $\dot{E}_{\text {co }}$ phases are only sensitive to $\alpha$ (Fig. $4 \mathrm{a}, \mathrm{b}$ ). Whereas $\dot{E}_{\text {inter }}$ remains approximately constant around $13 \mathrm{~mm} \mathrm{yr}^{-1}, \dot{E}_{\mathrm{co}}$ increases from 11 to $22 \mathrm{~mm} \mathrm{yr}^{-1}$ when $\alpha$ increases from $15-45^{\circ}$.

The resulting Coulomb stresses $\triangle C F F_{\mathrm{E} \text {-inter }}$ and $\triangle \mathrm{CFF}_{\mathrm{E}-\mathrm{co}}$ on the fault plane are in turn sensitive to (1) the dip angle $\alpha$, which controls both the distribution and amplitude of $\dot{E}_{\text {inter }}$ and $\dot{E}_{\mathrm{co}}$ and the distance between the Earth surface and the fault plane, and (2) the effective friction $\mu^{\prime}$ by amplifying the influence of normal stress on the Coulomb stress (Fig. 4c,d). The maximum values of $\triangle C F F_{\mathrm{E}-\text { inter }}$ and $\triangle \mathrm{CFF}_{\mathrm{E}-\mathrm{co}}$ obtained on the fault plane show similar distributions in the parameter space. $\triangle C F F_{\mathrm{E} \text {-inter }}$ is minimum $\left(\sim 1 \times 10^{-3}\right.$ bar yr $\left.^{-1}\right)$ for a low effective friction $\left(\mu^{\prime} \leq 0.2\right)$ combined to a high or low dip angle $\left(15^{\circ}\right.$ or $\left.45^{\circ}\right)$, whereas it increases when increasing $\mu^{\prime}$ and reaches a maximum $\left(\sim 2.7 \times 10^{-3}\right.$ bar yr $\left.^{-1}\right)$ for $\alpha$ around $25^{\circ} . \Delta \mathrm{CFF}_{\mathrm{E}-\mathrm{co}}$ is minimum $\left(\sim 1.5 \times 10^{-2}\right.$ bar yr $\left.^{-1}\right)$ for a low effective friction $\left(\mu^{\prime} \leq 0.2\right)$ combined to a high or low dip angle $\left(15^{\circ}\right.$ or $\left.45^{\circ}\right)$, whereas it increases when increasing $\mu^{\prime}$ and reaches a maximum of $\sim 4 \times 10^{-2}$ bar yr $^{-1}$ for $\alpha$ around $30^{\circ}$.

Because the Coulomb stresses induced by tectonics $\triangle C F F_{\mathrm{T} \text {-inter }}$ are also sensitive to the Young modulus $E$, the ratios $\triangle C F F_{\mathrm{E}-\text { inter }} /$ $\triangle C F F_{\mathrm{T} \text {-inter }}$ and $\triangle C F F_{\mathrm{E}-\mathrm{co}} / \triangle C F F_{\mathrm{T} \text {-inter }}$ are in turn sensitive to $\alpha, \mu^{\prime}$ and $E$. Increasing the Young modulus from 10 to 20 or $50 \mathrm{GPa}$ increases $\triangle C F F_{\mathrm{T} \text {-inter }}$ and decreases $\triangle C F F_{\mathrm{E} \text {-inter }} / \triangle C F F_{\mathrm{T} \text {-inter }}$ and $\triangle C F F_{\mathrm{E}-\mathrm{co}} / \triangle C F F_{\mathrm{T}-\text { inter }}$ by a factor of 2 or 5 , respectively. $\triangle C F F_{\mathrm{E}-}$ inter $/ \triangle C F F_{\mathrm{T} \text {-inter }}$ remains lower than one only for all the models tested, independent of the Young modulus $E$. At the contrary, $\triangle C F F_{\mathrm{E}-\mathrm{co}} / \triangle C F F_{\mathrm{T} \text {-inter }}$ displays a large domain in the parameter space with values greater than one (that is, with at least one element of the fault plane dominated by stresses induced by erosion). For $E=10 \mathrm{GPa}$, only models with low $\mu^{\prime}(<0.5)$ and high $\alpha\left(>35^{\circ}\right)$ are dominated by tectonic stresses $\left(\triangle C F F_{\mathrm{E}-\mathrm{co}} /\right.$ $\left.\triangle C F F_{\mathrm{T} \text {-inter }}<1\right)$, whereasile for $E=50 \mathrm{GPa}$, most of the models with $\alpha$ greater than $20-30^{\circ}$ are dominated by tectonic stresses. Therefore, Coulomb stresses induced by erosion during the seismic cycle represent a significant contribution to fault stress loading, even though their amplitude depends on the properties of the fault (dip angle, effective friction) and of the medium (Young modulus).

\section{Discussion}

Based on erosion data from Taiwan ${ }^{19}$, we have demonstrated that the elastic Coulomb stresses induced by erosion are of the order of $\sim 0.5 \times 10^{-3} \mathrm{baryr}^{-1}$ on the thrust faults located in the western foothills and reach a maximum of $\sim 4 \times 10^{-3} \mathrm{bar} \mathrm{yr}^{-1}$ on the Liuchia fault. These results are consistent with the outcomes from a simple model of the seismic cycle of a thrust fault that accounts for the effect of both erosion and tectonics, using fault properties and a slip velocity close to the ones inferred for Taiwan ${ }^{20-22}$. Coulomb stresses induced by inter-seismic $\triangle C F F_{\mathrm{E}-\text { inter }}$ and co-seismic $\triangle C F F_{\mathrm{E}-\mathrm{co}}$ erosion and averaged over the duration of a seismic cycle $(\sim 500 \mathrm{yr})$ reach values of up to $\sim 3 \times 10^{-3}$ bar yr $^{-1}$ and $\sim 8 \times 10^{-2}$ bar yr $^{-1}$, respectively. 
On the shallower part of thrust faults $(<5 \mathrm{~km}$ deep), the ratio of the Coulomb stresses induced by co-seismic erosion $\triangle C F F_{\mathrm{E}-\mathrm{co}}$ to the ones induced by tectonic loading $\triangle C F F_{\mathrm{T} \text {-inter }}$ is about equal to one for a Young modulus $E=10 \mathrm{GPa}(\sim 0.2$ for $E=50 \mathrm{GPa})$ and even reach a maximum of $\sim 20$ closer to the surface $(\sim 4$ for $E=50 \mathrm{GPa}$ ). In addition, assuming that co-seismic erosion happens only during a period 10-100 times shorter 25,26 $(\sim 5-50 \mathrm{yr})$ than the complete seismic cycle ${ }^{23}(\sim 500 \mathrm{yr})$, $\triangle C F F_{E-C O}$ increases up to $80 \times 10^{-1}$ to $8 \mathrm{bar} \mathrm{yr}^{-1}$ and the ratio $\triangle C F F_{\mathrm{E}-\mathrm{co}} / \triangle C F F_{\mathrm{T} \text {-inter }}$ to 10 or 100 for $E=10 \mathrm{GPa}(2-20$ for $E=50 \mathrm{GPa}$ ) during the first $\sim 5-50$ years following a large earthquake. Large earthquakes with a potential negative mass balance (that is, erosion greater than uplift), such as the Wenchuan earthquake ${ }^{24,27}$, could induce even higher rates of $\triangle C F F_{\mathrm{E}-\text { co }}$ than those predicted by a steady-state model. Our modelling approach imposes that co-seismic erosion is maximum close to the fault trace and above the shallower part of thrust faults (Fig. 3). This result contrasts with most of the observed distribution of earthquake-triggered landslides, with a maximum of landslide density close to the epicentral area, and therefore generally above the deeper part of thrust faults ${ }^{28}$. Therefore, depending on the location of large earthquake hypocenters along the fault plane, our estimates for the contribution of co-seismic erosion to fault stress loading might likely be overestimated.

However, our results emphasize that short-lived and intense erosional events associated with efficient sediment transport, such as typhoons, could suddenly increase the Coulomb stress of underlying faults. On longer time-scales, climatic changes or transition between fluvial- and glacial-dominated surface processes could also lead to high transient erosion rates and therefore to transient increases of the fault stress loading due to erosion ${ }^{4-7}$. The mechanism proposed in this study is limited neither to convergent settings nor to erosion only, as sediment deposition on the hanging wall of normal faults could also lead to a significant increase in Coulomb stress ${ }^{5}$. Moreover, some less active areas, such as intra-continental faults or old orogens still experience intense erosion and episodic seismic activity ${ }^{6,7}$. In the absence of major tectonic deformation, surface processes could significantly contribute to the stress loading of faults in these areas, even when considered independently of the stresses induced by isostatic rebound.

In summary, our results demonstrate that surface processes represent a significant contribution to the Coulomb stress loading of faults during the seismic cycle. In terms of deformation, these additional stresses on the shallower part of fault planes can induce and trigger shallow earthquakes, as illustrated by the seismicity triggered by the large 2013 Bingham Canyon mine landslide ${ }^{35}$, or potentially favour the rupture of large deeper earthquakes up to the surface as, for instance, during the Chi-Chi earthquake ${ }^{36}$. This offers new perspectives on the mechanisms influencing stress transfers during the seismic cycle, as well as on seismic hazard assessment in areas experiencing rapid erosion. More generally, Coulomb stress loading of faults induced by surface processes over short time scales provides an additional positive feedback between climate, surface processes and tectonics.

\section{Methods}

Seismic cycle model. The deformation model computes the velocity field $\mathbf{v}$, strain $\dot{\boldsymbol{\varepsilon}}$ and stress $\dot{\boldsymbol{\sigma}}$ rate tensors induced by surface erosion in a $3 \mathrm{D}$ elastic half-space based on the Boussinesq approximation ${ }^{37}$. With respect to this approximation, we assume that the model surface is horizontal (Fig. 1). The effect of such assumption is here limited as the topography of the western foothills of Taiwan is globally $<1 \mathrm{~km}$. The model is discretized by cubic cells with a $100 \mathrm{~m}$ resolution, with a Young modulus of $E=10 \mathrm{GPa}$, a Poison ratio of $v=0.25$ and a rock density of $\rho=2800 \mathrm{~kg} \mathrm{~m}^{-3}$.
Velocity, stresses and strain induced by tectonics are simulated by the mean of triangular dislocations ${ }^{30,31}$ accounting for the slip (1) of a viscous deep shear zone during the inter-seismic phase and of (2) a frictional fault located in the shallow elastic-brittle crust during the co-seismic phase. The imposed averaged tangential velocities of the shear zone $V_{\text {inter }}$ and of the fault $V_{\text {co }}$ are both equal to $40 \mathrm{~mm} \mathrm{yr}^{-1}$. Coulomb stress changes are then computed by projecting the stresses due to surface processes and to tectonics on the fault plane that is discretized with a resolution of $100 \mathrm{~m}$. The extent of fault planes and the dip angle data of the western foothills of Taiwan were simplified from ref. 22. Each fault trace was simplified to a line segment that best reproduces the real fault trace geometry.

Elastic Boussinesq model. We here consider the displacements, stress and strain components generated by a point load $\mathrm{F}$ at the surface of a 3D semi-infinite elastic solid of coordinates $x, y$ and $z$, with $z$ being positive downward. Let's define

$r=\sqrt{\left(x-x_{0}\right)^{2}+\left(y-y_{0}\right)^{2}+z^{2}}$ the distance to the point load of location $\left(x_{0}, y_{0}, z\right)$, $\Delta x=x-x_{0}$ and $\Delta y=y-y_{0}$. The elasticity of the model is described by the Lamés first $\lambda$ and second parameters $\mu$, which are related to the Young modulus $E$ and the Poisson ratio $v$ by $\lambda=E v /((1+v)(1-2 v))$ and $\mu=E /(2(1+v))$ For $z \geq 0$, the displacement components are ${ }^{37,38}$ :

$$
\begin{aligned}
& U x(x, y, z)=\frac{F}{4 \pi}\left(\frac{\Delta x}{(\lambda+\mu) r(z+r)}-\frac{\Delta x z}{\mu r^{3}}\right) \\
& U y(x, y, z)=\frac{F}{4 \pi}\left(\frac{\Delta y}{(\lambda+\mu) r(z+r)}-\frac{\Delta y z}{\mu r^{3}}\right) \\
& U z(x, y, z)=\frac{F}{4 \pi}\left(\frac{(\lambda+2 \mu)}{\mu(\lambda+\mu) r}+\frac{z^{2}}{\mu r^{3}}\right)
\end{aligned}
$$

Assuming infinitesimal deformation, the symmetric Cauchy strain tensor $\varepsilon$ is then obtained by differentiating the displacement vector, $\varepsilon_{i j}=1 / 2\left(d U_{i} / d x_{j}+d U_{j} / d x_{i}\right)$. For an isotropic medium, the stress components are then given by the following equation, $\sigma_{i j}=\lambda \delta_{i j} \varepsilon_{k k}+2 \mu \epsilon_{i j}$, where $\delta_{\mathrm{ij}}$ is the Kronecker delta. The six stress components are ari, $^{37,38}$ :

$$
\begin{aligned}
& \sigma_{x x}(x, y, z)=\frac{F}{2 \pi}\left(\frac{3 \Delta x^{2} z}{r^{5}}+\frac{\mu\left(\Delta y^{2}+\Delta z^{2}\right)}{(\lambda+\mu) r^{3}(z+r)}-\frac{\mu z}{(\lambda+\mu) r^{3}}-\frac{\mu \Delta x^{2}}{(\lambda+\mu) r^{2}(z+r)^{2}}\right) \\
& \sigma_{y y}(x, y, z)=\frac{F}{2 \pi}\left(\frac{3 \Delta y^{2} z}{r^{5}}+\frac{\mu\left(\Delta x^{2}+z^{2}\right)}{(\lambda+\mu) r^{3}(z+r)}-\frac{\mu z}{(\lambda+\mu) r^{3}}-\frac{\mu \Delta y^{2}}{(\lambda+\mu) r^{2}(z+r)^{2}}\right) \\
& \sigma_{z z}(x, y, z)=\frac{F}{2 \pi}\left(\frac{3 z^{3}}{r^{5}}\right) \\
& \sigma_{x y}(x, y, z)=\frac{F}{2 \pi}\left(\frac{3 \Delta x \Delta y z}{r^{5}}-\frac{\mu \Delta x \Delta y\left(z+r^{2}\right)}{(\lambda+\mu) r^{3}(z+r)^{2}}\right) \\
& \sigma_{x z}(x, y, z)=\frac{F}{2 \pi}\left(\frac{3 \Delta x z^{2}}{r^{5}}\right) \\
& \sigma_{y z}(x, y, z)=\frac{F}{2 \pi}\left(\frac{3 \Delta y z^{2}}{r^{5}}\right)
\end{aligned}
$$

Because the model is linear and elastic, the total displacement, stress and strain components for any distribution of surface load are then computed by summation of the displacement, stress and strain components obtained for each individual point load.

Taiwan erosion rates. Erosion rates in Taiwan were calculated from fluvial suspended sediment load measured over the $30 \mathrm{yr}$ before the $1999 M_{w} 7.6 \mathrm{Chi}-\mathrm{Chi}$ earthquake, considering that the total fluvial sediment load contains $70 \%$ of suspended $\operatorname{load}^{9}$ (Fig. 1b). Erosion rates were calculated assuming that suspended sediment load, measured at 130 gauging stations, represents $70 \%$ of the river total sediment load, and that catchment-wide erosion rates correspond to the total sediment load divided by sediment density and by drainage area ${ }^{19}$. The smoothed erosion map of Fig. 1 was then obtained using a circular averaging window with a radius of $30 \mathrm{~km}$. The spatial resolution of the erosion map, even though coarse, still allows for resolving potential heterogeneities of $\triangle C F F$ induced by erosion between different faults and along each individual fault plane.

\section{References}

1. Dahlen, F. A. \& Barr, T. D. Brittle frictional mountain building: 1. Deformation and mechanical energy budget. J. Geophy. Res. 94, 3906-3922 (1989).

2. Willett, S. D. Orogeny and orography: The effects of erosion on the structure of mountain belts. J. Geophy. Res. 104, 28957-28981 (1999).

3. Beaumont, C., Jamieson, R. A., Nguyen, M. H. \& Lee, B. Himalayan tectonics explained by extrusion of a low-viscosity crustal channel coupled to focused surface denudation. Nature 414, 738-742 (2001).

4. Cattin, R. \& Avouac, J. P. Modeling mountain building and the seismic cycle in the Himalaya of Nepal. J. Geophy. Res. 105, 13389-13407 (2000).

5. Maniatis, G., Kurfeß, D., Hampel, A. \& Heidbach, O. Slip acceleration on normal faults due to erosion and sedimentation-results from a new three-dimensional numerical model coupling tectonics and landscape evolution. Earth Planet. Sci. Lett. 284, 570-582 (2009). 
6. Calais, E., Freed, A. M., Van Arsdale, R. \& Stein, S. Triggering of New Madrid seismicity by late-Pleistocene erosion. Nature 466, 608-611 (2010).

7. Vernant, P. et al. Erosion-induced isostatic rebound triggers extension in low convergent mountain ranges. Geology 41, 467-470 (2013).

8. Scholz, C. H. The Mechanics of Earthquakes and Faulting 439 (New York: Cambridge University Press, 1990).

9. Doglioni, C., Barba, S., Carminati, E. \& Riguzzi, F. Role of the brittle-ductile transition on fault activation. Phys. Earth Planet. In. 184, 160-171 (2011).

10. Cowie, P. A., Scholz, C. H., Roberts, G. P., Faure Walker, J. P. \& Steer, P. Viscous roots of active seismogenic faults revealed by geologic slip rate variations. Nat. Geosci. 6, 1036-1040 (2013).

11. Jaeger, J. C. \& Cook., N. G. W. Fundamentals of Rock Mechanics 3rd edn (London: Chapman and Hall, 1979).

12. Bettinelli, P. et al. Seasonal variations of seismicity and geodetic strain in the Himalaya induced by surface hydrology. Earth Planet. Sci. Lett. 266, 332-344 (2008).

13. Heki, K. Seasonal modulation of interseismic strain buildup in northeastern Japan driven by snow loads. Science 293, 89-92 (2001).

14. Reasenberg, P. A. \& Simpson, R. W. Response of regional seismicity to the static stress change produced by the Loma Prieta earthquake. Science 255, 1687-1690 (1992).

15. King, G. C., Stein, R. S. \& Lin, J. Static stress changes and the triggering of earthquakes. Bull. Seism. Soc. Am. 84, 935-953 (1994).

16. Stein, R. S. The role of stress transfer in earthquake occurrence. Nature 402 605-609 (1999)

17. Delescluse, M. et al. April 2012 intra-oceanic seismicity off Sumatra boosted by the Banda-Aceh megathrust. Nature 490, 240-244 (2012).

18. Segall, P., Desmarais, E. K., Shelly, D., Miklius, A. \& Cervelli, P. Earthquakes triggered by silent slip events on Kilauea volcano, Hawaii. Nature 442, 71-74 (2006).

19. Dadson, S. J. et al. Links between erosion, runoff variability and seismicity in the Taiwan orogen. Nature 426, 648-651 (2003).

20. Yu, S. B., Chen, H. Y. \& Kuo, L. C. Velocity field of GPS stations in the Taiwan area. Tectonophysics 274, 41-59 (1997).

21. Simoes, M. \& Avouac, J. P. Investigating the kinematics of mountain building in Taiwan from the spatiotemporal evolution of the foreland basin and western foothills. J. Geophy. Res. 111, B10401 (2006).

22. Shyu, J. B. H., Sieh, K., Chen, Y. G. \& Liu, C. S. Neotectonic architecture of Taiwan and its implications for future large earthquakes. J. Geophy. Res. 110, B08402 (2005).

23. Chen, W. S. et al. Late Holocene paleoseismicity of the southern part of the Chelungpu fault in central Taiwan: Evidence from the Chushan excavation site. B. Seismol. Soc. Am. 97, 1-13 (2007).

24. Parker, R. N. Mass wasting triggered by the 2008 Wenchuan earthquake is greater than orogenic growth. Nat. Geosci. 4, 449-452 (2011).

25. Hovius, N. et al. Prolonged seismically induced erosion and the mass balance of a large earthquake. Earth Planet. Sci. Lett. 304, 347-355 (2011).

26. Howarth, J. D., Fitzsimons, S. J., Norris, R. J. \& Jacobsen, G. E. Lake sediments record cycles of sediment flux driven by large earthquakes on the Alpine fault, New Zealand. Geology 40, 1091-1094 (2012).

27. Li, G. et al. Seismic mountain building: landslides associated with the 2008 Wenchuan earthquake in the context of a generalized model for earthquake volume balance. Geochem. Geophys. Geosyst. 15, 833-844 (2014).
28. Meunier, P., Hovius, N. \& Haines, J. A. Topographic site effects and the location of earthquake induced landslides. Earth Planet. Sci. Lett. 275, 221-232 (2008).

29. Lague, D., Hovius, N. \& Davy, P. Discharge, discharge variability, and the bedrock channel profile. J. Geophy. Res. 110, F04006 (2005).

30. Meade, B. J. Algorithms for the calculation of exact displacements, strains, and stresses for triangular dislocation elements in a uniform elastic half space. Comput. Geosci. 33, 1064-1075 (2007).

31. Vergne, J., Cattin, R. \& Avouac, J. P. On the use of dislocations to mode interseismic strain and stress build-up at intracontinental thrust faults. Geophys. J. Int. 147, 155-162 (2001).

32. Loevenbruck, A., Cattin, R., Le Pichon, X., Courty, M. L. \& Yu, S. B. Seismic cycle in Taiwan derived from GPS measurements. C. R. Acad. Sci. IIA 333, 57-64 (2001)

33. Dominguez, S., Avouac, J. P. \& Michel, R. Horizontal coseismic deformation of the 1999 Chi-Chi earthquake measured from SPOT satellite images: Implications for the seismic cycle along the western foothills of central Taiwan. J. Geophy. Res. 108, 2083 (2003).

34. Hsu, Y. J., Simons, M., Yu, S. B., Kuo, L. C. \& Chen, H. Y. A two-dimensiona dislocation model for interseismic deformation of the Taiwan mountain belt. Earth Planet. Sci. Lett. 211, 287-294 (2003).

35. Pankow, K. L. et al. Massive landslide at Utah copper mine generates wealth of geophysical data. GSA. Today 24, 4-9 (2014).

36. Cattin, R., Loevenbruck, A. \& Le Pichon, X. Why does the co-seismic slip of the 1999 Chi-Chi (Taiwan) earthquake increase progressively northwestward on the plane of rupture? Tectonophysics 386, 67-80 (2004)

37. Boussinesq, J. Équilibre d'élasticité d'un sol isotrope sans pesanteur, supportant différents poids. CR Math. Acad. Sci. Paris 86, 1260-1263 (1878).

38. Westergaard, H. M. Theory of elasticity and plasticity (Harvard University Press, 1952).

\section{Acknowledgements}

We are grateful to Patience Cowie, Dimitri Lague, Philippe Davy, Thomas Croissant, Niels Hovius, Patrick Meunier, Odin Marc and Frédéric Boudin for discussions. This study was funded by the CNRS-INSU (Centre National de la Recherche Scientifique Institut National des Sciences de l'Univers, France), the ORCHID program (Partenariats Hubert Curien, France-Taiwan), the EROQUAKE ANR project (Agence Nationale de la Recherche, France) and the Université Rennes 1. This is IPGP contribution number 3569.

\section{Author contributions}

P.S. analyzed the data and performed the modelling. All authors contributed equally to the design of the study and to the writing of the paper.

\section{Additional Information}

Supplementary Information accompanies this paper at http://www.nature.com/ naturecommunications

Competing financial interests: The authors declare no competing financial interests

Reprints and permission information is available online at http://npg.nature.com/ reprintsandpermissions/

How to cite this article: Steer, P. et al. Erosion influences the seismicity of active thrust faults. Nat. Commun. 5:5564 doi: 10.1038/ncomms6564 (2014). 